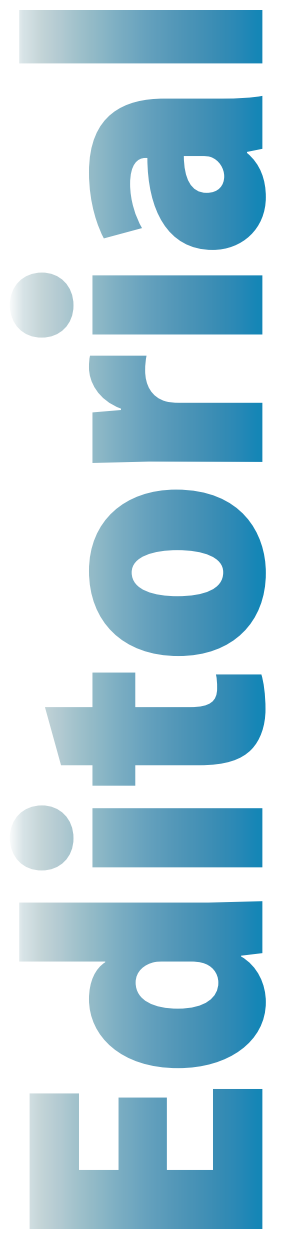

\title{
Les huiles végétales
}

Le gras a suscité des réactions d'horreur chez des générations de professionnels de la santé et de la nutrition, abhorré ! Faut-il pour autant l'adorer ? Ce n'est pas en ces termes que les problématiques de nutrition doivent être posées.

Avec ce volumineux dossier spécial sur les huiles végétales, la réponse illustrée est tout en nuance. Les corps gras sont des trésors de variété, de richesse, de diversité. Loin de les fuir, apprenons à les connaître, à les apprivoiser.

Ce ne sont pas avant tout des réserves de calories mais des sources d'acides gras, dont les fonctions biologiques et les effets spécifiques sont multiples. Un " plus " est ainsi attribué à celles qui sont riches en acide $\alpha$-linolénique (oméga-3) : colza, germe de blé, noix, cameline, chanvre, périlla, lin, etc.

Chaque corps gras a son empreinte spécifique, sa signature en acides gras : c'est ainsi également pour les corps gras d'origine animale, dont le beurre est le roi, avec ses 400 acides gras différents, mais il n'est pas sur notre table... de lecture aujourd'hui.

Le secret des huiles réside cependant davantage dans leur insaponifiable, c'està-dire dans leur partie non lipidique, celle qui ne permet pas la formation de savons. Les molécules en sont extrêmement nombreuses : polyphénols en tout genre, terpènes, stérols, hydroxytyrosol, caroténoïdes et tocophérols, etc. Elles confèrent à chaque huile ses propriétés à visée cardiovasculaire ou antiproliférative qui ne sont pas seulement l'apanage des "stars" telle que l'huile d'olive, mais aussi de l'huile d'argan qui pourrait lui ravir la vedette, ou encore de l'huile de nigelle, de pépin de courge, d'argousier...

Vous serez ainsi enchanté en découvrant avec Pierre Weill que le lin n'a pas qu'un usage textile, mais qu'il fait un retour de force en nutrition; avec Ahmed Adlouni que l'huile d'argan n'est pas d'abord destinée à la cosmétique mais à l'alimentation santé ; avec Kamel Ghédira et Rémy Le Jeune que l'huile de nigelle (provenant des graines de cumin noir) n'a pas qu'un passé dans l'Antiquité des tombes égyptiennes mais connaît un renouveau pharmacologique; avec Paul Grossin que l'huile de périlla avait fait ses preuves en Chine ou au Japon, il y a plusieurs siècles, avant d'émerger en Occident; avec Loïc Bureau que l'huile de chanvre ne doit plus faire peur! Avec Paul Goetz que l'huile de graine de courge mérite le détour pour ses effets en urologie, et que l'huile d'argousier est réputée dans toute l'Eurasie...

Vous ne serez pas déçu par la nouvelle mise au point très large de Franck Gigon et al. sur l'huile d'olive, valeur sûre par excellence. 
Vous serez séduit par le panorama diététique et gastronomique que Michèle Cahuzac fait des huiles : véritable jungle technicoréglementaire et culinaire dont on sort vivant. Vous apprécierez peut-être la saga historicoscientifique que je dresse de la nutrition et des huiles.

Ainsi, de la nutrition à la nutrithérapie en passant par la phytothérapie, les huiles ont aujourd'hui leurs lettres de noblesse qui leur donnent une place de choix légitime dans le cortège de "nos amis les aliments ».

Alors, goûtez et voyez.

J.-M. Lecerf

Service de nutrition, Institut Pasteur de Lille, 1, rue du Professeur-Calmette, BP 245,

F-59019 Lille cedex, France

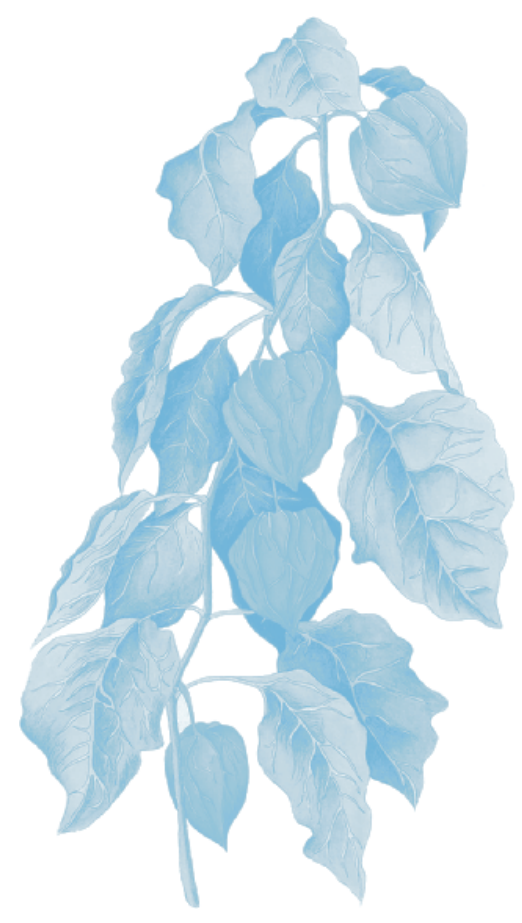

